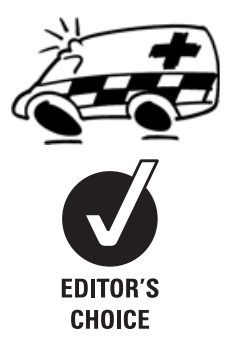

${ }^{1}$ Rescue 1122, Punjab Emergency Service, Lahore, Pakistan

${ }^{2}$ Department of Emergency Medicine, Aga Khan University. Karachi, Pakistan

Correspondence to Dr Hunniya Waseem, Rescue 1122, Punjab Emergency Services, IH-70 Falcon Complex Gulberg 3, Lahore 75500, Pakistan;

hunniyawaseem@hotmail.com

Accepted 7 August 2010 Published Online First 15 September 2010

\title{
Establishing a successful pre-hospital emergency service in a developing country: experience from Rescue 1122 service in Pakistan
}

\author{
Hunniya Waseem, ${ }^{1}$ Rizwan Naseer, ${ }^{1}$ Junaid Abdul Razzak ${ }^{2}$
}

\begin{abstract}
As in many other developing countries, emergency medical services, especially pre-hospital emergency care, has long been neglected in Pakistan. Consequently, patients are brought to the emergency departments by relatives or bystanders in private cars, taxis or any other readily available mode of transportation. Ambulances, where they exist, have barely a stretcher and arrangements for oxygen supply. Modern emergency services are considered too costly for many countries. A model of pre-hospital emergency services, called Rescue 1122 and established in Punjab province of Pakistan, is presented. The system is supported by government funding and provides a quality service. The article describes the process of establishment of the service, the organisational structure, the scope of services and the role it is currently playing in the healthcare of the region it serves.
\end{abstract}

\section{PRE-HOSPITAL EMERGENCY CARE IN LOW- AND MIDDLE-INCOME COUNTRIES}

In developing countries vertical, disease focused interventions have traditionally been the focus of healthcare investments. Emergency medical services including, both hospital and pre-hospital emergency services, have been long neglected in many countries of the developing world. ${ }^{12}$

Evidence exists for deaths prevented and disability averted for diseases such as trauma, pregnancy, myocardial infarctions, strokes and sepsis by strengthening emergency services. ${ }^{1}{ }^{3} 4$ Pre-hospital care research in developing countries, to a large extent, has focused on the consequences of trauma and injury. Injury accounts for $16 \%$ of the global burden of disease and overwhelmingly affects low and middle income countries. ${ }^{5}$ The two trauma related publications of WHO-Guideline of Essential Trauma Care 2005 and Pre-hospital Trauma Care System 2005-have played an important role in highlighting the need for pre-hospital and hospital based emergency services.

Emergency services assume greater importance where access block due to a variety of factors, such as lack of health insurance, leads to poor availability of preventive and routine healthcare. ${ }^{7}$ Healthcare needs, resources and cultural context in developing countries is likely to impact the scope, structure, function and the modes of financing of emergency services. The model of emergency care in developing countries as compared to developed countries has been more focused on an affordable, rudimentary emergency medical service rather than quality. Therefore, almost no literature exists for a government run, quality conscious pre-hospital care system in developing countries. ${ }^{8}$

\section{EMERGENCY SERVICES IN PAKISTAN}

Until a few years ago Pakistan did not have an organised emergency medical services system. ${ }^{9-13}$ The patients were brought to the hospital either by bystanders or in rudimentary patient transport vehicles containing a simple stretcher and a siren. These patient transport vehicles had no trained emergency medical technicians (EMTs) or emergency equipment, and no system of communication with hospitals. ${ }^{14} 15$

\section{EMERGENCY SERVICES IN PUNJAB}

Punjab, the most populated province of Pakistan, with a population of around 90 million, ${ }^{16}$ has 11 public and 17 private medical colleges and around 40 teaching hospitals. ${ }^{17}$ However, emergency medical services rely on decades old emergency departments, no triage, no permanent physician staff and little or no pre-hospital care. ${ }^{18}$ Emergency medicine is not part of the curriculum of any of the major government or private medical institutions. Similarly, undergraduate medical education does not have mandatory rotation in emergency departments.

In 2004 the government of Punjab launched the Rescue 1122 pilot project from the provincial capital of Punjab with the vision of providing professional pre-hospital emergency services for the urban cities of the province. The service works through an emergency toll free number, 1122, which can be easily accessed through landline and mobile phones. After the success of the Rescue 1122 pilot project, the service has been expanded to all 35 districts of Punjab and is now being replicated by other provinces of Pakistan. This service has so far provided emergency care to 498000 people, while maintaining its standard and average response time of $7 \mathrm{~min}$ in all districts.

\section{STEPS TOWARDS ESTABLISHMENT OF RESCUE 1122}

In the following sections we describe a successful model of Emergency Medical Service (EMS) in Pakistan.

\section{Providing legislative framework}

Twenty months after the establishment of Rescue 1122, the provincial assembly formally passed the Punjab Emergency Service Act 2006 on 9 June 2006, mandating the establishment of emergency services 
for the purpose of maintaining a state of preparedness to deal with emergencies, in order to provide a timely response, rescue and emergency medical treatment to the persons affected by the emergencies and to recommend measures to be taken by related organisations to avoid emergencies. ${ }^{19}$

\section{Human resource development}

The first batch of rescuers was trained by a trauma surgeon who was motivated to start this EMS after observing first hand the helplessness and mismanagement of trauma victims in Pakistan. He started the training in the borrowed premises of Elite Police Training school with a focus on rescue, triage and basic life support. At the same time, work was commenced on further development and refinement of curriculum. Subsequently, in order to ensure sustainable human resource development, a makeshift Emergency Services Academy has also been established in a renovated bus terminal. The training for EMTs lasts for 4 months. All the EMTs are certified Medical First Responders and are able to provide basic life support, cardiopulmonary resuscitation, spinal immobilisation, oxygen and intravenous fluids and basic analgesia, and are familiar with use of the automatic external defibrillator. Besides medical training, EMTs are trained in dispatch, documentation, and water and fire rescue. The dispatch training is according to locally developed guidelines. Other emergency care providers such as fire rescuers, disaster emergency responders and ambulance drivers are also given basic medical training. None of the trainees have advanced cardiac life support training.

\section{Putting up an organisational structure}

The service operates in all districts of the province, with plans to expand to the rural areas. All of the districts are directly under the command of the headquarters which is located in the provincial capital and is directed by the Director General of Rescue 1122. Each district is headed by a district emergency officer and a subordinate emergency officer responsible for smooth running of the service, during both routine as well as mass casualty events. Each district has a control room which functions as a dispatch centre, and various rescue stations housing ambulances, fire and rescue vehicles. The headquarters is responsible for policy guidelines, development, recruitment and training, and quality monitoring through a provincial monitoring cell. However, for day to day administrative support the district emergency officer reports to the local district head.

\section{Construction of ambulance stations}

The construction of ambulance stations has taken place according to response time rather than population served. For example, in Lahore city which has a population of 8 million, there is one central station, in the heart of the city, which houses the control room of the district. Fourteen stations are built around it almost in a circumferential distribution. Strategically located, it has been calculated that each of these stations can respond to calls in its radius within $7 \mathrm{~min}$.

Twenty-four ambulances in this city are distributed in three patterns:

1. Fixed deployment of ambulances in the above mentioned 14 stations.

2. One ambulance is also present in each of the four fire stations owned by Rescue 1122 so that in case of a fire incident both the fire engine and ambulance can respond together.

3. Key points or hotspots have been identified in the city. These are the places where most road traffic accidents take place.
During rush hours some ambulances are deployed on these key points daily.

This city receives an average of 170 calls daily. This amounts to one ambulance responding to seven calls daily. They are not allowed to refuse any calls of surgical or medical emergencies, however they do not transport discharged patients from hospital or do inter-hospital transfers. The low number of calls to this service can be explained by either a culture of relatives taking patients to hospitals directly or by the presence of other informal ambulances in the city, which do all transports including emergency ones.

\section{Pre-hospital care}

The ambulance staff consists of one driver and two EMTs. On scene they provide first aid, splinting, basic life support in case of cardiac arrest, and transport of patients with immobilisation. As yet they can prescribe only simple analgesia and sublingual glyceryl trinitrate in case of chest pain. Further guidelines for medication use are under review.

The EMTs spend minimum time at the scene and are instructed to transport patients to pre-designated hospitals as soon as possible. In case of mass casualty incidents a 'scoop and run' policy is used. The scene time is not calculated as yet by the service, however the response time of $7 \mathrm{~min}$ is well-calculated as is the roundabout time which has an average of $1 \mathrm{~h}$.

\section{Expanding the scope of service}

Rescue 1122, which initially started as an ambulance service, has over time expanded its scope to include the following other services:

- Fire services

- Rescue services

- Disaster response teams

- Community safety programme

It was soon realised that in order for this new service to operate it will not be possible for them to only remain in the domain of pre-hospital care. The fire services in Pakistan had not been modernised for ages and the service was often delayed and ineffective. In 2007, Rescue 1122 was assigned the task of starting a modern fire service. Fire engines were bought and the formal training of firemen took place with the help of the Strathclyde Fire Service and Rescue Service in Glasgow, UK. To date, they have participated in around 15000 fire incidents and saved property worth US\$ 232.56 million. ${ }^{20}$

In the aftermath of the October 2005 earthquake, disaster response teams were established which received training to deal with natural and manmade disasters. They have participated in about 1000 building collapse incidents and about 250 explosions. Though relatively new, they have made a difference in disaster management by contributing to smooth transferring and triaging of patients. ${ }^{10}$

To ensure availability of trained rescuers in the event of major disaster and emergencies community response teams have been developed under the umbrella of Rescue 1122.

\section{Monitoring quality of service}

A GPS (global positioning system) fleet tracking system has been developed with a street map which is linked to a centralised tracking system being monitored and analysed in control rooms and provincial monitoring cells. This system watches the movement of all vehicles and is also used to track response times. Furthermore, all calls received are also monitored with a comprehensive call monitoring software. Conventional 
methods of quality improvement are also used, such as report reviews and critical incident reviews.

Because of this astringent surveillance the service has been able to maintain an average response time of $7 \mathrm{~min},{ }^{21}$ which is impressive considering the bad road conditions, heavy traffic and congested areas of the cities in which it operates, typical of any developing country. This is in itself an achievement as it is comparable to response times in high income countries.

\section{KEY LESSONS LEARNT}

Some of the reasons why Rescue 1122 is a low-cost viable model for EMS services which can be replicated elsewhere in the developing world are as follows:

1. Local manufacturing of the required infrastructure is possible in Pakistan. All vehicles used by the services, including ambulances, fire engines, aerial platforms and rescue vehicles have been indigenously developed in Pakistan, following international standards. This has saved a foreign exchange of US\$ 25.58 million. The local manufacturing has also facilitated the maintenance and repair of vehicles.

2. The service stations have been established according to the response time rather than the target population as discussed above. This can be a model for other developing nations because more people can be served with less resources.

3. The instructors of the Academy were certified as trainers for Medical First Responder and Collapsed Structure Search and Rescue courses from the Programme for Enhancement of Emergency Response Programme of United States Agency for International Development. Since then the 4 month training has been taken over by these instructors, incurring a bare minimum average expenditure of Rupees 19902 (US\$ 234) per trainee. So far a total of 6112 rescuers have been trained.

4. All the training and teaching manuals have been adapted where necessary for local needs and some have been translated. This has further helped in reducing costs.

5. The Emergency Ambulance, Rescue and Fire Service is run under a single command and control structure. This was done to avoid confusion, especially during disaster situations where a break in communications is a major pitfall. Its actual impact on outcomes of disaster response needs to be studied through prospective studies.

\section{CONCLUSION}

Rescue 1122 has managed to set up a low cost, effective system of pre-hospital care which can be replicated in other developing countries with little or no modification. Almost all the recommendations of the World Health Organization guidelines for pre-hospital trauma care systems have been fulfilled. However, prospective and retrospective clinical trials are needed to verify the efficacy of the system and its role in the healthcare sector.
The role of the system should not be restricted to a vertical provision of healthcare services; with training and interaction with the community, it can be also be used for horizontal provision such as preventive medicine, vaccination and women's health. The community safety programmes, which are encouraging the community to participate as first responders and are propagating injury prevention, are a major step in that direction. The presence of a pre-hospital set-up will also prove to be very beneficial in strengthening emergency medicine as a specialty in the country, and further training of paramedics and fellowship programmes for doctors can be an interesting venue for expansion. ${ }^{22}$

Acknowledgements We thank Dr Kiran Ejaz, Research Associate, Department of Emergency Medicine, Aga Khan University Hospital, Karachi for checking the first draft of the manuscript.

Competing interests HW is the acting Deputy Director (Research) and RN is the Director of General Rescue 1122, Punjab Emergency Service.

Provenance and peer review Not commissioned; externally peer reviewed.

\section{REFERENCES}

1. Razzak JA, Kellermann AL. Emergency medical care in developing countries:is it worthwhile? Bull World Health Organ 2002;80:900-5.

2. Shah MN. The formation of the emergency medical services system. Am J Public Health 2006:96:414-23.

3. Mock CN, Adzotor KE, Conklin E, et al. Trauma outcomes in the rural developing world: comparison with an urban level I trauma center. J Trauma 1993;35:518-23.

4. London JA, Mock CN, Quanash RE, et al. Priorities for Improving Hospital-Based Trauma Care in an African City. J Trauma 2001;51:747-53.

5. Mock C, Lormand JD, Goosen J, et al. Guidelines for essential trauma care. Geneva: World Health Organization, 2004.

6. Sasser S, Varghese M, Kellerman A, et al. Prehospital trauma care systems. Geneva, Switzerland: World Health Organization, 2005.

7. Dib JE, Naderi S, Sheridan IA, et al. Analysis and applicability of the Dutch EMS system into countries developing EMS systems. J Emerg Med 2006;30:111-15.

8. Lockey DJ. Pre-hospital trauma management. Resuscitation 2001:48:5-15.

9. Umer M, Sepah YJ, Shahpurwala MM, et al. Suicide bombings: process of care of mass casualties in the developing world. Disasters 2009;33:809-21.

10. Naseer R. Study of the emergency response services. Report for the UNDP. Pakistan Office and the Ministry of Interior, Government of Pakistan. 2002.

11. Raftery KA. Emergency medicine in southern Pakistan. Ann Emerg Med 1996:27:79-83.

12. Mehdi IJ. Emergency medicine in Pakistan. Ann Emerg Med 1996;27:84-8.

13. Naseer MR, Awais SM. Epidemiology of trauma victims. Pak J Surg 1994;Vol 10, No 3:84-7.

14. Channa R, Jaffrani HA, Khan AJ, et al. Transport time to trauma facilities in Karachi an exploratory study. Int J Emerg Med 2008;1:201-4.

15. Jat AA, Khan MR, Zafar $\mathrm{H}$, et al. Peer review audit of trauma deaths in a developing country. Asian J Surg 2004;27:58-64.

16. Government of Pakistan. National Institute of Population Survey. Islamabad, Pakistan: Government of Pakistan, 2001

17. Pakistan Medical and Dental Council. Official Website: dev.plexushosting.com/ PMDC.

18. Razzak JA, Hyder AA, Akthar $T$, et al. Assessing emergency medical care in low income countries: a pilot study from Pakistan. BMC Emerg Med 2008;8:8

19. The Punjab Emergency Service Act. 2006. http://punjablaws.gov.pk/laws/484.html.

20. Anon. Five year Performance Report of Rescue 1122. Lahore: Ferozesons, 2009.

21. Jooma R, Khan SJ, Razzak JA. The Trauma Centre: what it should mean. J Pak Med Assoc 2008;58:530-1.

22. MacFarlane C, van Loggerenberg C, Kloeck W. International EMS systems in South Africa: past, present and future. Resuscitation 2005;64:145-8. 